\title{
ADMISSIONS TO BRITISH UNIVERSITIES
}

$\mathrm{T}$ HE second report of an ad hoc committee of the Committee of Vice-Chancellors and Principals of the Universities of the United Kingdom on Procedure for Admission of Students (pp. vi+3l. London : Association of Universities of the British Commonwealth, 1960. 2s.) deals first with the action taken by the universities on some procedural recommendations of an earlier report published in May 1958 by an ad hoc committee. Although the new system has been in operation for only one full year, it is already clear that a marked improvement has occurred. Indeed, 86 per cent of heads of schools answering the independent inquiry of the Joint Committee of the Four Secondary Associations about delays by universities were satisfied that there was no unreasonable delay, and 66 per cent were satisfied with the decisions themselves. Throughout the universities, all those concerned are showing the utmost willingness to co-operate in making the selection and admission of students as simple, fair and rapid a process as possible. As all those concerned, in universities and schools, become more accustomed to the new procedures, the improvement should continue, and to this end the Committee recommends that the normal date for the receipt of applications should continue to be January 31 of the year in which entry is desired (the preceding November 30 for medicine, etc.); constant care should be exercised to preserve standards of precision in letters making offers of places, and the great importance of making as many early decisions as possible is specially emphasized. The Committee also reviews some con- tinuing problems such as multiple interviews and clearing houses, and recommends that experiments should be tried, worked by volunteer professors in limited fields such as chemistry, physies. biology, medicine, dentistry, veterinary science. agriculture and law. Finally, it recommends that the admission of students generally be kept under review. The Committee of Vice-Chancellors and Principals has already invited this ad hoc committee to continue its consideration of future problems.

Figures for applications and admissions for 1959 show that applications to university institutions in England, Wales and Scotland were $117,300,7,600$ and 9,100 , respectively, and the corresponding admissions to first-degree courses were $14,960,1,650$ and 3,720 , respectively. As between the main categories, applications were distributed as follows : arts, 50,900 ; pre-science, 40,700 ; technology, 21,700; medicine, 13,100 ; dentistry, 4,500. The ratio of applications to the number of places available varies widely between individual universities; for example, from $6 \cdot 0$ to $11 \cdot 4$ in England, $3 \cdot 8$ to $6 \cdot 2$ in Wales, and 1.9 to 3.0 in Scotland, but no clear pattern, according to age or type of institution, emerged from more detailed examination of the figures.

Appended to the report is a brief guide for the sixth-former entitled "Getting into a University", containing the minimum information which any intending candidate needs before diseussing matters with those who will give him advice and before completing his application.

\section{INTERNATIONAL UNION FOR CONSERVATION OF NATURE AND NATURAL RESOURCES}

$\mathrm{R}$. LEVEQUE was appointed by Unesco to undertake a new mission to the Galapagos Islands. The purpose was to consolidate the basis for the establishment of a research laboratory, the primary objective of the Charles Darwin Foundation. He has now presented a report which contains a wealth of information about the destruction being wrought on the exceptional fauna of the archipelago*.

In his inventory of the present state of the animal populations, Levêque recalls that the sea-Iion has succeeded in holding its own in face of the depredations of fishermen, but the fur-bearing seal (Arctocephalus australis) is prey to exploitation which will soon lead to extinction if drastic measures are not taken. Biological study of the species must be a priority in the programme of research.

Concerning the bird populations, the maintenance of which is bound up with the survival of the shrub cover of the islands, Levêque is less pessimistic. The larger species call for attention : albatross, flightless cormorant, penguins and especially the flamingo, which is in keen demand for its feathers, and consequently vulnerable.

* Bulletin of the International Union for Consertation of Nature and Tatural Resources, 9, Nos. 1-2 (1960).
The author has nothing essential to add to the excellent material on reptiles previously compiled by Mr. Eibl-Eibesfeldt. Wild pig destroy the eggs of the sea iguana, but apart from this the latter species is practically without enemies; the land iguana is holding its own.

By far the most threatened species is the giant tortoise; the local position is desperate. The massacres continue, with the destruction of eggs by feral pigs, by trading shells, and extraction of oil. It appears necessary to destroy the foral pig if the tortoise is to be saved. Levêque calls for the establishment of a large park to be fenced off with barbed wire, and gives suggestion for its boundaries.

Crayfish are being captured on a reckless soale; a single boat recently brought in three tons of cray. fish tails in a few days; a thorough study of the biology of the species is required. Likewise, overfishing of the bacaleo will soon result in a serious depletion of this species.

The author lays strong emphasis on the disastrons consequences resulting from the introduction of exotic species to the Islands: dog, donkey, but especially pigs, "the worst enemy of the indigenous 
agriculture, flora and fauna", and feral goats, which are on the increase and destroy numbers of plants. It would seem advisable to encourage unrestricted hunting of these animals; the fate of the Galapagos Islands, otherwise, will be similar to that of the Mexican island of Guadeloupe. Levêque emphasizes the mistake of prohibiting hunting of feral animals introduced to the Islands. The result is contrary to the objective pursued; the defenceless native fauna, the destruction of which does not require the use of fire-arms, pays the consequences and serves as food for the settlers.

A number of sound recommendations conclude the survey : engagement of an experienced botanist to undertake methodical inventory of the plant species represented; careful study of the biology of the land tortoise, and, later, of both iguanas, Amblyrhynchus and Conolophus; efforts in the fields of oceanography and meteorology resulting in a marine research scheme and the establishment of climatological stations.

\title{
INDUSTRIAL HEALTH
}

\begin{abstract}
$\checkmark \overrightarrow{\mathrm{H}} \mathrm{E}$ annual report of the Chief Inspector of Factories on Industrial Health in 1959 follows the pattern of the two previous separate reports, and this year includes a special chapter on "Dusts and Their Effects on the Lungs"*. The establishment at headquarters of the new pathological laboratory permitted a substantial increase in the number and variety of tests, and the combined chemical and pathological work has made possible the examination of an increasing number of workers. The Chief Inspector again emphasizes his anxiety to foster the liaison between the medical branch of the Inspectorate and members of the medical profession generally, which he regards as of great importance if due weight is to be given to significant occupational factors in the health of work people. The 532 cases of industrial poisoning or diseases, notified under the Factories Act, 1937, and the Lead Paint Act, included 64 nonfatal cases of lead poisoning, 6 cases ( 1 fatal) of anthrax and 25 non-fatal cases of aniline poisoning ; 226 notified cases of epitheliomatous ulceration included 9 fatalities, and there were 192 cases of chrome ulceration, while 14 of the 206 gassing accidents were fatal.

The First Aid in Factories Order, 1938, was super. seded by the First Aid Boxes in Factories Order,

* Ministry of Labour. Annual Report of the Chief Inspector of Factories on Industrial Health, 1959. Pp. iii +60. (Cmnd. 1137.) (I.ondon : H.M. Stationery Office.) 3s. 6d. net.
\end{abstract}

1959 , on January 1, 1960, which brings the contents more into line with modern practice than under the 1938 Order. Interdepartmental discussions on the general principles of first-aid treatment were attended by independent medical experts nominated by the Medical Research Council and mombers of the Advisory Panel in Ophthalmology were consulted on the first-aid treatment of eye injuries, while at the two meetings during the year of the Industrial Health Advisory Committee the possibility of developing and extending mədical supervision in factories was the main subject discussed.

Publication of a new booklet, "Toxic Substances in Factory Atmospheres", was approved. The special chapter on dusts and their effects on the lungs points out that it is now becoming increasingly doubtful whether it is safe to assume that any finely divided dust is harmless if inhaled in sufficient quantity over a sufficient period. Certain dusts, too, may produce an acute inflammatory response in the lungs when they are breathed, and others, usually after many years, may bring about a cancerous development in some part of the respiratory tract. The chapter outlines some general principles on measures required to protect workers against inhaling injurious dusts as well as briefly summarizing existing knowledge about the action of particular classes of dusts.

\section{X-RAY DIFFRACTION STUDIES OF THERMALLY DECOMPOSED PERMANGANATES}

\author{
By P. J. HERLEY and DR. E. G. PROUT \\ Chemistry Department, Rhodes University, Grahamstown, South Africa
}

$\mathrm{T}$

HE thermal decomposition of crystals of silver ${ }^{1}$, potassium $^{2}$, rubidium $^{3}$, cæsium $^{4}$ and barium $^{5}$ permanganates in high vacuum yield pressure-time plots which are sigmoid in form. The plots for the decomposition of crystals of potassium permanganate (13.6 mgm.) and silver permanganate $(20.6 \mathrm{mgm}$.) at $217^{\circ} \mathrm{C}$. and $110^{\circ} \mathrm{C}$, respectively, are shown in Figs. 1 and 2. The acceleratory and decay portions of the curves for the above permanganates, except silver permanganate, are deseribed by the ProutTompkins equation ${ }^{2}$ :

$$
\log \left[p /\left(p_{f}-p\right)\right]=k t+c
$$

where $p_{f}$ is the final pressure. The plots for the decomposition of silver permanganate obey a modified form of the equation ${ }^{x}$, namely :

$$
\log \left[p /\left(p_{f}-p\right)\right]=k \log t+c
$$

These equations follow if it is assumed that at the commencement of the acceleratory period strain exists in the crystal at the interface between the product formed prior to acceleration and the undecomposed material. This strain produces micro cracks in the reactant surface, and the reaction progresses inwards by a mechanism of branching planes of reaction. Mechanical disruption of the erystal, as in the case of potassium permanganate, is a consequence, not the cause, of branching. Silver permanganate, for example, does not disintegrate during reaction. It is of interest, therefore, to examine the Laue photographs of potassium permanganate and silver permanganate at different stages during decomposition when lattice distortion would be expected for both substances. Such distortion will be shown by asterism of the diffraction spots. Fig. 3, $A, B, C, D$, $E, F, G$ were taken at $40 \mathrm{kV}$. and $20 \mathrm{~m}$.amp. using 